\title{
A presentificação no tempo e espaço da clínica psicológica online: relato de experiência
}

\author{
La presentificatión en el tiempo y el espacio de la clínica psicológica en línea: informe \\ de experiencia
}

\author{
The presentification in time and space of the online psychological clinic: experience \\ report
}

\author{
Mônica Fortuna Pontes \\ Universidade do Estado do Rio de Janeiro (UERJ), Rio de Janeiro - RJ/Brasil \\ ORCID: 0000-0002-4319-9385 \\ E-mail: m.fortunapontes@gmail.com
}

\begin{abstract}
Resumo
De um dia para o outro, compulsoriamente, passamos a atender nossos pacientes através de um computador ou de um telefone, devido a pandemia do novo coronavírus. Desafios de um contexto inédito se impuseram no campo da psicologia clínica e da psicanálise. Adentrávamos um tempo e espaço desconhecidos e, ao caminhar, construíamos outros caminhos. Pistas cartográficas ofereceram elementos para pensar as relações psicoterápicas num novo momento e o num novo espaço. Assim, a partir das vivências nos contextos da clínica psicológica privada e dos acolhimentos psicológicos institucionais, realizados de forma online, este texto tem o objetivo de apontar e discutir inquietações por mim experimentadas, bem como questões suscitadas durante o período de quarentena. Através do que chamei de "cronologia das novidades, da resistência às surpresas" abordo os impactos sentidos no modo de trabalho online, constato horizontalidades nas relações marcadas pela assimetria do encontro psicoterapêutico e reconheço presença corporal nas conexões virtuais.
\end{abstract}

Palavras-chaves: Psicoterapia; Sistemas de apoio psicossocial; Sistemas on-line; Pandemia.

\begin{abstract}
Resumen
De un día al otro, empezamos a atender obligatoriamente a nuestros pacientes a través de un ordenador o un teléfono, por la pandemía del nuevo coronavirus. Se han planteado retos de un contexto sin precedentes en el campo de la psicología clínica y el psicoanálisis. Entramos en un tiempo y espacio desconocidos y, mientras caminábamos, construimos otros caminos. Los rastros cartográficos ofrecían elementos para pensar en las relaciones psicoterapéuticas en un nuevo momento y en un nuevo espacio. Así pues, a partir de las experiencias en los contextos de la clínica psicológica privada, y del apoyo psicológico institucional realizada en línea, este texto tiene por objeto señalar y discutir las preocupaciones que experimenté, así como las cuestiones planteadas, durante el período de cuarentena. A través de lo que he llamado "cronología de novedades, de resistencia a las sorpresas" me acerco a los impactos que se sienten en el trabajo en línea, observo la horizontalidad en las relaciones marcadas por la asimetría del encuentro psicoterapéutico y reconozco la presencia corporal en las conexiones virtuales.
\end{abstract}

Palabras clave: Psicoterapia; Sistemas de apoyo psicosocial; Sistemas en línea; Pandemia.

\footnotetext{
Abstract

From one day to the next, we compulsorily started to attend our patients through a compute or a telefone, due to the pandemic of the new coronavirus. Challenges of an unprecedented context have been imposed in the field of clinical psychology and psychoanalysis. We entered an unknown time and space and, passing through it, we built other paths. Cartographic trails offered elements to think about psychotherapeutic relationships in a new moment and in a new space. Thus, from the experiences in the contexts of the private psychological clinic, and from the institutional psychological support online, this text aims to point out and discuss the worries I experienced, as well the questions raised, during the quarantine period. Through what I have called "the chronology of novelties of the resistance to surprises", I approach the impacts felt in the online work mode. I have found horizontalities in the relationships marked by the asymmetry of the psychotherapeutic encounter, and I have recognized the body presence in the virtual connections.
} 
Keywords: Psychotherapy; Psychosocial support systems; Online systems; Pandemic.

De um dia para o outro, em março de 2020, compulsoriamente, passamos a atender nossos pacientes através da tela de um computador ou de um telefone, devido à pandemia do novo coronavírus. Uma quantidade pequena de profissionais tinha essa experiência. Desafios inéditos se impuseram para psicoterapeutas e psicanalistas. Como se dariam, dali para frente, as relações já estabelecidas com pacientes, ou as que se iniciariam desta forma? Adentrávamos um tempo e espaço desconhecidos, e ao caminhar construíamos um novo caminho, até porque "no hay camino, se hace camino al andar", como nos escreve Antonio Machado (1912/n.d).

Uma nova estrada estava sendo percorrida e criada, agora no ambiente online. A referência teórica e prática com a qual trabalho, a psicoterapia reichiana, funcionou como auxiliar no percurso. Assim, utilizada como pista cartográfica, ofereceu elementos para pensar as relações psicoterápicas num novo momento e o num novo espaço. Proposta por Deleuze e Guattari, a abordagem cartográfica, "tomada como um mapa em constante processo de produção, instaurando um processo de experimentação contínua", me possibilitava criar novas diretrizes, novas formas de enxergar a realidade, num permanente esgarçar do conhecido e buscar de equilíbrio (Zambenedetti \& Silva, 2011, p. 457).

\footnotetext{
${ }^{1} \mathrm{O}$ projeto objetiva oferecer acolhimento psicológico online à comunidade interna da UERJ, durante o período de distanciamento social, devido à pandemia do novo coronavírus. Os acolhimentos são destinados aos/às: docentes, servidores técnico-administrativos, alunos e alunas dos diversos campi da UERJ. Seu funcionamento se deu de abril até agosto de 2020. Os acolhimentos foram realizados por um grupo de voluntários e voluntárias formado por profissionais da psicologia e psicanálise, estudantes, ex-estudantes de pós-graduação e docentes do Instituto de Psicologia (IP), totalizando 41 profissionais. O Projeto Psicologia, Presente! é coordenado por Claudia Cunha, Edna Ponciano (na primeira fase), Laura Quadros e Vitor Gomes, docentes
}

Os corpos de psicoterapeutas, analistas e de pacientes, nos dois tempos e espaços da clínica psicológica, ou seja, antes no consultório e durante o distanciamento social, em casa, são afetados e tocados pelos acontecimentos recentes e produzem efeitos. Tais acontecimentos impulsionaram a criação de redes de prestações de serviços psicológicos online, como forma de acolher parte da população. Uma delas trata-se do projeto Psicologia, Presente! ${ }^{1}$ da Universidade do Estado do Rio de Janeiro (UERJ), o qual faço parte e ao qual farei referência algumas vezes na composição do presente ensaio. Desta forma, a partir das vivências nos contextos da clínica psicológica privada, e dos acolhimentos psicológicos institucionais, ambos realizados de forma online, este texto tem o objetivo de apontar e discutir inquietações por mim experimentadas, bem como questões suscitadas, durante o período de quarentena.

Cabem esclarecimentos sobre a distinção que faço quando me refiro aos processos psicoterápicos e aos acolhimentos psicológicos. Os primeiros são contínuos, sem número de encontros preestabelecidos e se dão no contexto da clínica privada. Já os acolhimentos psicológicos se caracterizam por contatos pontuais, geralmente um ou dois encontros entre profissional psi e solicitante, e são realizados no âmbito do projeto Psicologia, Presente! Sendo assim, para expor pontos importantes frente aos momentos

do IP. Contou com as seguintes parcerias: Núcleo de Saúde Mental/Policlínica Piquet Carneiro - NSM/PPC (psiquiatria) e Psicologia Médica do Hospital Universitário Pedro Ernesto - Psimed/HUPE (rede de apoio), além do apoio do IP. Na primeira fase do projeto, que ocorreu de 5 de abril de 2020 até 4 de maio de 2020, 173 pessoas foram atendidas. $\mathrm{Na}$ segunda fase do projeto, iniciada dia 4 de maio, os acolhimentos oferecidos passaram a ser tanto no formato individual quanto em grupo. A partir desta data, 9 grupos de apoio terapêuticos online, gerais e específicos começaram a funcionar: idosos, estudantes, mulheres e profissionais de saúde (CUNHA, 2020) 
desconcertantes pelos quais passamos desde o início da quarentena, recorro à Conceição Evaristo no livro Insubmissas lágrimas de mulheres. Evaristo (2016, p. 81), em uma das entrevistas que fez com mulheres negras para compor o referido livro escreve: "Para mim, uma conversa, ainda mais que eu estava ali para ouvir, tinha de ser olho no olho".

Me pergunto, como fazê-lo na atualidade? Mais especificamente no contexto dos acolhimentos psicológicos e psicoterapias. Em encontro recente, a psicanalista Jô Gondar ${ }^{2}$ interrogou sobre como cruzar o olhar nas telas dos computadores, se quando olhamos para a câmera ou quando olhamos para a tela. Vale discutir se o olho no olho das relações prescinde da presença física. $\mathrm{E}$, no caso de não haver a imagem, quando dos encontros realizados sem câmera, ou seja, pelo telefone, poderiam eles, justamente, apaziguar incômodos provocados pelo olhar, vivido como invasor? Nós, psicoterapeutas e psicanalistas que fazemos os acolhimentos e os atendimentos, lidamos com essas e tantas outras questões emergidas ou reativadas desde o início das intervenções online, ao mesmo tempo em que estamos também vivendo as consequências da pandemia.

\section{Cronologia das novidades, da resistência às surpresas}

Em meados de março, dando início ao período de distanciamento social, deixei de ir ao consultório, e propus sessões através do uso das ferramentas virtuais disponíveis. Dando, assim, continuidade aos processos psicoterápicos de cada um dos indivíduos atendidos. Eram relações psicoterápicas já estabelecidas, algumas há anos. Até então, eu possuía apenas uma pequena experiência com atendimentos online. Eles haviam sido realizados por motivo de viagem, minha ou de pacientes, e todos eles através da câmera de vídeo.

\footnotetext{
${ }^{2}$ Segunda Transmissão ao vivo do Grupo Brasileiro de Pesquisas Sándor Ferenczi, dia 26 abril 2020, intitulado "A Elasticidade da técnica em tempos de Covid-19", https://www.youtube.com/watch?v=jlv60RAwjzs
}

A minoria das pessoas atendidas apresentou resistência e as sessões através dos computadores e celulares se iniciaram. A migração do espaço do consultório para o ambiente online, com vídeo, foi feita. Consciente do meu preconceito relacionado ao formato, um pensamento me acompanhava: " $E$ o que temos no momento".

Os desdobramentos do trabalho online, tanto dos atendimentos contínuos, na clínica privada, quanto dos acolhimentos no projeto da UERJ foram me chamando atenção ao longo das semanas pela profundidade alcançada. Talvez porque eu não esperasse muito da "nova" forma de contato.

Pouco tempo depois de deixar de trabalhar no consultório físico, o projeto de acolhimento psicológico da UERJ, o Psicologia, Presente! teve início. O primeiro acolhimento que realizei pelo projeto, em abril, aconteceu através de chamada de áudio, não de vídeo, porque assim a pessoa preferiu. Fui surpreendida com a preferência da solicitante. $\mathrm{Eu}$ deixei que ela escolhesse a forma mais confortável, sem ter me dado conta de como seria para mim, "apenas" ouvir, e não ver. $\mathrm{Me}$ refiz do imprevisto e segui, me questionando sobre as repercussões daquela forma de conexão. Nas semanas subsequentes eu ouvi o seguinte de solicitantes do projeto, que também preferiram que o acolhimento fosse feito sem imagem: "com o vídeo, minha internet fica ruim", "ah! prefiro por áudio só" e "estou deitada, acabei de almoçar, prefiro por áudio".

Entre justificativas de problemas na rede e a opção por maior conforto, eu já não me espantava mais com a preferência. Para mim, o áudio, pelos efeitos que percebi durante estes encontros de acolhimento, tinha deixado de ser pouco. Minha experiência clínica, até aquele momento, era do trabalho realizado frente-afrente, olhando para o paciente, sendo olhada, observando seus movimentos, expansões e contenções corporais. Psiquismos e corpos 
sendo percebidos conjuntamente através de um corpo que é psíquico. Sempre atenta ao que ouvia, certamente, mas também ao que via. Contudo, estava aperfeiçoando outras possibilidades. No caso, a da apreensão através da voz, entonações e silêncios. Em muitas ocasiões, houve mesmo vantagens nos encontros de vozes e sem a visão do olho.

Acompanhei e testemunhei muitas emoções, queixas, dores físicas e psíquicas e diversas tentativas de lidar com 0 distanciamento social, a pandemia e seus efeitos. Dentre aquelasouvidas nos acolhimentos dos plantões do projeto Psicologia, presente! eu destaco: ansiedades, tremores, dores de cabeça, choros e tristezas; preocupações com o futuro, tonturas, ânsias de vômito e prostrações; falta de concentração, irritação; taquicardias, faltas de ar, sensações de desmaio quando o "mundo fica muito grande", perdas e insônias; uso de chás, práticas de meditação, yoga, acompanhadas pela música e os subterfúgios nas arrumações infindáveis; interrogações sobre "se estou ou não com o vírus", descontos na comida, busca pelo sol, a companhia dos filmes e séries; sofrimentos solitários de jovens que moram com pai e mãe ou sozinhos, risos e choros simultâneos, aumento das brigas em família, o desejo de ficar só; raiva do presidente, revolta e culpa; depressão e reconhecimento de que já se vivia em quarentena há anos; asma, problemas respiratórios, tremores nos olhos, altos e baixos; falas como: "voltei à estaca zero" $\mathrm{e}$ mais choro.

$\mathrm{Eu}$, emprestando minha escuta, minha voz e presente através delas, muitas vezes sorria do outro lado da linha, ao ouvir o seguinte, após alguns dos acolhimentos: "alguém está me entendendo", ou "o papo [foi] muito bom, vou até tomar um chazinho em homenagem à nossa conversa". Quem ficava agradecida era eu. Eu também estava sendo acolhida e recebendo suporte naqueles momentos. Nós, psicoterapeutas, assim como pacientes ou solicitantes do projeto, nos encontramos numa relação que comporta assimetrias. Assimetrias porque uma parte busca acolhimento e a outra oferece, ainda que não haja fronteiras definidas entre dar e receber. Segundo Reis (2004, p. 13):

A experiência clínica se funda em um pedido dirigido por alguém que sofre a um outro, para que este desvende a natureza do mal que o atormenta. [...]. Ninguém sai incólume do processo iniciado por esse pedido, uma vez que seus protagonistas, embora em lugares e papéis distintos, afetam-se mutuamente em um delicado jogo de forças.

$\mathrm{Na}$ atualidade, tal assimetria é ainda mais porosa, pois é atravessada pela ameaça viral invisível, trazendo uma horizontalidade para a relação. Mais do que nunca "o psicanalista, ao contrário [do etnólogo que estuda culturas e universos distintos dos seus], sabe que o mundo em que mergulha com seus clientes é exatamente como o seu" (REIS, 2004 , p. 38). O que não significa perda da assimetria. Santos (2020, p. 49) esclarece que horizontalidade e simetria não são sinônimos e que "a assimetria entre analista e analisando deve se manter como um dos fundamentos da prática psicanalítica, seja ela em tempos de crise/pandemia ou não".

Estamos vivendo os fantasmas e desafios que nossos pacientes e pessoas que acolhemos estão enfrentando, guardando, claro, a certeza de que as realidades sociais não são uniformes, tampouco as subjetividades. Contudo, fomos aproximados do terror da finitude. Procuramos nos ocupar, negamos aqui e ali a atual realidade, mas ela vai se impondo. A pergunta formulada por pacientes: "você está bem?", hoje vai além do "tudo bem?" social, encobre o "você está se cuidando?" e transparece a ameaça do desamparo, agora direcionado à figura do/a psicoterapeuta. Sigo, assim, caminhando e cartografando, no dia-adia da clínica online, um mapa de experimentações "tendo como características a abertura e a conectividade, sendo suscetível de receber modificações constantemente diferentemente do decalque, que volta sempre 'ao mesmo"' (Zambenedetti \& Silva, 2011, p. 457). 
Retomando a cronologia dos fatos, ainda em meados de abril, um paciente novo me procurou buscando atendimento na clínica privada. Seria inédito para mim dar início a um novo processo de psicoterapia através da tela de um computador. Uma coisa era dar continuidade a uma psicoterapia, agora de forma online, com um vínculo já estabelecido, outra coisa seria começar uma nova relação desta forma.

Apesar da estranheza, a primeira vez que nos vimos foi através do vídeo, e é desta forma que a relação permanece até o momento. Ele, uma pessoa que estava levando a vida em função de não se contaminar pelo novo coronavírus. Passava as horas de seus dias atento aos detalhes, nada poderia sair de seu controle para que não fosse dominado pelo terror maior. Jogar o lixo na lixeira de seu prédio era motivo para desorganização interna. Hoje, alguns meses depois, ele sai em viagens na segurança de seu carro e vislumbra, novamente, um futuro.

Poucas semanas depois deste primeiro contato com o rapaz mencionado, no final de abril, uma outra pessoa me procurou. Ela veio encaminhada pelo projeto da UERJ e, o que seria alguns encontros de acolhimento tomou a forma de um acompanhamento psicoterápico. Como já ocorrera no contexto dos acolhimentos, ela também preferiu que as sessões fossem realizadas sem imagem. Ela apresentou suas justificativas objetivas e subjetivas para abrir mão da tela. Mantivemos assim, durante alguns meses, os encontros através das chamadas telefônicas. Foram contatos semanais com uma moça cuja imagem eu imaginava, e ela também. Recentemente, após alguns meses de experiência e reflexões sobre a clínica online, e com um vínculo mais estabelecido com a referida paciente, propus um primeiro contato através do vídeo, ainda que isso pudesse tocar em questões sensíveis para ela, relacionadas a sua imagem. A simples proposta da inserção da tela trouxe interessantes desdobramentos na dinâmica terapeuta/paciente e, o primeiro encontro com contato visual me forneceu elementos para compreender aspectos já surgidos durante as sessões. Além disso, sua imagem, no primeiro momento, acabou por provocar uma certa dispersão de minha parte. Aquela relação anteriormente estabelecida através "somente" das vozes, fora perturbada, e isso é algo que ainda busco esclarecer no contexto deste caso. O formato das próximas sessões não será definido previamente e sim na sequência dos encontros que virão. Nessa perspectiva, o manejo cartográfico oferece a possibilidade de tratar o enquadre de outra forma, sem deixá-lo, obviamente, de lado, mas com maior acompanhamento dos fluxos (Passos, Kastrup, \& Escóssia, 2009).

Diante de tantas novidades, fui me deixando deslocar de um terreno de certa forma conhecido, acho que nunca conhecido totalmente, de anos de trabalho na clínica, para algum outro pouco conhecido, e me permitindo levar, pelas novas marés. Sem buscar encaixes em algo já familiar, mas respeitando os movimentos pedidos pelo novo momento. Segundo Deleuze (1992/2013, p. 155), "o fundamental é como se fazer aceitar pelo movimento de uma grande vaga, de uma coluna de ar ascendente, 'chegar entre' em vez de ser origem de um esforço". Assim, sigo.

Passei da resistência às boas surpresas, no acolhimento, no atendimento contínuo, na minha própria análise, essa última, parte fundamental de todo um percurso profissional. Em conversas com profissionais e colegas pude constatar que compartilhamos tais percepções da "nova" experiência.

Meses se passaram e já estamos em setembro de 2020. Dando continuidade ao trabalho de forma online, pode-se dizer que andamos fazendo coisas que não fazíamos: atendendo em horários que não costumávamos atender; marcando sessões de acordo com a disponibilidade da rede ou quando a privacidade é possível; lidando com sessões interrompidas porque a luz da tela causou enxaqueca na paciente, entre outras. Tudo isso acompanhado pelos constantes: "você tá me ouvindo?". 


\section{Referências corporais}

Costumamos diferenciar os atendimentos presenciais e os online. Entretanto, diante de tantas intensidades e retomando questões colocadas no início, não há como continuar sustentando que os encontros online são encontros não-presenciais. Joel Birman, em conferência online recente ${ }^{3}$, ressaltou a presença do corpo do analista através da imagem na tela e através de sua voz. E que formas intensas de presença!

Sobre os aspectos que envolvem a (não) materialidade dos corpos em encontros online, imagens e vozes de pacientes e psicoterapeutas (re)criam o setting em suas próprias casas. Compondo essa (re)criação, cultivei o hábito de utilizar os fones de ouvido durante os atendimentos. Sinto que me ajudam a manter a conexão e proximidade. Desta forma, vozes, silêncios e, quando há a tela, olhares e movimentos de pacientes vão dando o tom. Nos são solicitados outros sentidos para percebê-los neste "novo" espaço/tempo de corpos na clínica. Vamos, deste modo, apurando nossas sensibilidades através de uma outra lógica que vem nos sendo imposta. Seriam, então, outras formas de estarmos presentes enquanto profissionais, assim como outras formas de apreendemos o outro.

O cansaço nos atendimentos online experimentado por mim inicialmente, e relatado por muitos terapeutas e analistas no começo do isolamento social, talvez seja advindo daí, das tentativas de apreensão do outro através de velhas referências ${ }^{4}$. Hoje me canso menos.

Tenho acompanhado profundos e belos mergulhos nos processos psicoterápicos. E nos acolhimentos, onde os contatos são pontuais, nem por isso menos intensos e produtores de

\footnotetext{
${ }^{3}$ Conferência online intitulada "Uma leitura psicanalítica da pandemia", dia 16 de junho de 2020, https://www.youtube.com/channel/UCqjzV7Proe y5Nh qnNI-MwA
}

movimentos, tenho escutado interessantíssimos relatos e retornos. Não são relações distantes.

Observo também, na minha clínica, que as pessoas atendidas têm dito coisas que não diziam antes, avançado em temas importantes, elas próprias reconhecem isso. Possivelmente não falariam se fosse ao vivo. O que não é uma vantagem, em si. Na particularidade de cada história de vida e de cada encontro, alguns assuntos serão mesmo abordados de forma mais fluida, por alguns, no contato online, enquanto gerará dificuldade em outros. O formato online ou o atendimento no consultório será constantemente atravessado pelas singularidades. Não há um melhor que o outro. São distintos. A abordagem reichiana nos possibilita uma intervenção direta no corpo. Mas, apesar de saber que colegas, durante os atendimentos online, propõem aos pacientes trabalhos corporais, é através da palavra e da escuta que me faço presente e venho mobilizando couraças, consideradas por Reich (2004) o componente somático dos mecanismos de defesa. Segundo o referido autor, corpo e mente formam corpo psíquico. Este será tocado e afetado tanto através do trabalho verbal quanto do trabalho físico.

Gondar (2017, p.113) esclarece que:

[...] a linguagem é, ao mesmo tempo física e psíquica. Ela é física porque é articulada, porque a palavra, sonora ou visual, tem uma materialidade e faz parte do mundo material. Mas a linguagem também é psíquica em sua capacidade de representar e de produzir associações entre essas representações. A linguagem teria, assim, uma dupla natureza, sendo ao mesmo tempo corpo e psiquismo.

Assim, acompanho através dos encontros e sessões online as mais distintas formas das defesas se armarem e desarmarem.

\footnotetext{
${ }^{4}$ Tema levantado na segunda transmissão ao vivo do Grupo Brasileiro de Pesquisas Sándor Ferenczi, dia 26 abril 2020, intitulado "A Elasticidade da técnica em tempos de Covid-19”, http://www.youtube.com/watch?v=jlv60RAwjzs
} 
Defesas psíquicas são indispensáveis e estão operando bastante neste momento, em nós e nos pacientes. Nos defendem do grande terror,

uma vez que quase todos nós ainda pensamos como selvagens acerca desse tópico, não é motivo para surpresa o fato de que o primitivo medo da morte é ainda tão intenso dentro de nós e está sempre pronto a vir à superfície por qualquer provocação. (FREUD, 1919/2010, s.p).

O psicanalista Bruno Campos, ao comentar o filme de terror A Bruxa de Blair ${ }^{5}$, expõe nossas frágeis defesas e tentativas de trancarmos nossos fantasmas nos porões, mas que, por estarem dentro de nós, aparecem nos pequenos atos, gerando tensão. Na atualidade, ainda segundo comentário de Campos (2020), tais fantasmas se manifestam com frequência no movimento corriqueiro de pegarmos no álcool em gel, por exemplo.

Importante nos relacionarmos com eles, os fantasmas, ainda que contornando-os. Algo nada fácil. De acordo com Freud (1919/2010, s.p),

dificilmente existe outra questão, no entanto, em que as nossas ideias e sentimentos tenham mudado tão pouco desde os primórdios dos tempos, e na qual formas rejeitadas tenham sido tão completamente preservadas sob escasso disfarce, como a nossa relação com a morte.

Todos teremos medo. Que bom que podemos nos defender! Mas, indispensáveis também são as flexibilizações das couraças. Senão, seu enrijecimento nos engessa, provoca dor ou nos atira no perigo da negação. Sigo, assim, expectadora participante também das rígidas defesas. Minhas, dos que acolho e atendo, de familiares e colegas. Há pessoas que acharam, finalmente, a justificativa perfeita para abster-se de certos encontros, ou descobriram na limpeza infinita de suas casas a proteção e o abrigo das ameaças que assombram. Há também aquelas que buscam viver como se quase nada estivesse acontecendo, precisam se agarrar às suas vidas conhecidas e não deixaram de fazer as unhas em salões de beleza abertos à meia porta.

Esses exemplos mostram o quanto o medo de um descontrole psíquico pode se expressar nos excessos de ritos obsessivos, no caso da limpeza da casa, ou na negação, no caso das idas aos salões. Algumas defesas estão mais adaptadas às exigências atuais, individuais e coletivas, e protegem mais contra o vírus. Outras atitudes desprotegem. E revelam, por vezes, tentativas de controlar o incontrolável. Alguns comportamentos denotam negligência e são, muitas vezes, condenados. Todavia, estamos nos equilibrando em bruscas oscilações emocionais. Encontramo-nos diante do desamparo e da incerteza. $O$ não-saber desorganiza. Ninguém está confortável. Inventamos como atravessar o tempo, algumas pessoas deprimem enquanto outras enxergam vida onde não havia. Criar rotinas pode ser imprescindível: "faça exercícios e não fique de pijama", prescrevem os manuais. Isso está ajudando muita gente. Para outras pessoas, poder sentir o ritmo e as demandas do corpo psíquico, através do contato consigo, é uma conquista, ainda que sem exercícios e de pijama o dia todo. Viver o vazio também pode ser de grande valor, um ganho pessoal. Não há mesmo caminho fácil e eles são singulares.

Para finalizar, acho importante guardar a intenção de transformar todas essas novidades em algo. Então, recorrendo às palavras de Ailton Krenak (2019, p. 15): "vamos aproveitar toda nossa capacidade crítica e criativa [...]. Vamos pensar no espaço não como um lugar

\footnotetext{
${ }^{5}$ Live do dia 28 de junho de 2020 intitulada "Anatomia do medo em "A bruxa de Blair", da série "filmes mais psicanalíticos de todos os tempos", https://www.instagram.com/p/CB--wD9pfup/
} 
confinado, mas como o cosmos onde a gente

pode despencar em paraquedas coloridos".

\section{Referência}

Birman, J. (2020, junho 16). Uma leitura psicanalítica da pandemia. [Arquivo de vídeo]. Recuperado de

https://www.youtube.com/watch?v=LtEaiw $\underline{\mathrm{mXqao}}$

Campos, B. (2020, junho 28). Anatomia do medo em 'A bruxa de Blair', da série "filmes mais psicanalíticos de todos os tempos". [Arquivo de vídeo]. Recuperado de https://www.instagram.com/p/CB-wD9pfup/

Cunha, C. (2020, junho 8). Saúde mental em tempo de pandemia. [Arquivo de vídeo]. Recuperado de https://www.youtube.com/watch?v=Q7AP ZJygeek

Deleuze, G. (2013). Conversações. São Paulo, SP: Editora 34. (Obra original publicada em 1992).

Evaristo, C. (2016). Insubmissas lágrimas de mulheres. Rio de Janeiro, RJ: Malê Editora.

Freud, S. (2010). O inquietante. In S. Freud, Obras completas (P. C. de Souza, trad., v. XIV, s.p). São Paulo, SP: Companhia das Letras. (Trabalho originalmente publicado em 1919).

Gondar, J. (2017). As coisas e as palavras: Ferenczi e a linguagem. In E. Schueler Reis \& J. Gondar (Orgs.), Com Ferenczi. Clínica, Subjetivação, Política (pp.112121). Rio de Janeiro, RJ: 7 letras.

Gondar, J. (2020, abril 25). A Elasticidade da técnica em tempos de Covid-19 com Jô Gondar, Helia Borges e Bartholomeu Vieira. [Arquivo de vídeo]. Recuperado de https://www.youtube.com/watch?v=jlv60R Awjzs
Krenak, A. (2019). Ideias para adiar o fim do mundo. São Paulo, SP: Companhia das letras.

Machado, A. (n.d). Provérbios y cantares XXIX. In Campos de Castilla: Poesías completas. (Trabalho originalmente publicado em 1912). Recuperado de http://www.espacioebook.com/sigloxx_98/ machado/machado_camposdecastilla.pdf

Passos, E., Kastrup, V., \& Escóssia, L. (2015). Apresentação. In E. Passos, V. Kastrup, \& L. Escóssia (Org.), Pistas do método da cartografia. Pesquisa-intervenção e produção de subjetividade (pp. 7-16). Porto Alegre, RS: Sulina.

Reich, W. (1975). A função do orgasmo. São Paulo, SP: Editora Brasiliense.

Reis, E. (2004). De corpos e afetos, transferência e clínica psicanalítica. Rio de janeiro, RJ: Contra Capa.

Santos, L. (2020). Algumas reflexões sobre a clínica em tempos de pandemia. Revista da Sociedade de Psicanálise Iracy Doyle Ensaios, Psicanálise em tempos de pandemia, Edição especial digital, 48-51. Recuperado de https://drive.google.com/file/d/1ErBBccIL wnTnJh-

0YMtVYIcgD5ypE40H/view?fbclid=IwA R2Cpok0DpS9Oq39BsRmw2ddviePQyHngsu6Z op9eM9gvw728N6jRVGFtM

Zambenedetti, G., \& Silva, R. A. N. (2011). Cartografia e genealogia: aproximações possíveis para a pesquisa em psicologia social. Psicologia \& Sociedade, 23(3), 454463. doi: 10.1590/S0102$\underline{71822011000300002}$ 


\section{Dados sobre os autores:}

- Mônica Fortuna Pontes: Doutora em Psicologia Social pela UERJ (2019). Doutorado Sanduíche no Exterior (PDSE) na Université de Paris 8 (2017-2018). Mestre em Psicologia Clínica pela PUC-Rio (2011). Pesquisadora do GEPSID - Grupo de Estudos e Pesquisas Subjetividades e Instituições em Dobras. Especialista em Psicologia Clínica - CRP (2002). Possui formação em Psicoterapia Reichiana (2003) pela Núcleo de Psicoterapia Reichiana. Atua como psicóloga clínica desde 1990. Principais áreas de interesse e atuação: Homoparentalidades, Diversidade Sexual e Psicologia Clínica.

Declaração de Direito Autoral

A submissão de originais para este periódico implica na transferência, pelos autores, dos direitos de publicação impressa e digital. Os direitos autorais para os artigos publicados são do autor, com direitos do periódico sobre a primeira publicação. Os autores somente poderão utilizar os mesmos resultados em outras publicações indicando claramente este periódico como o meio da publicação original. Em virtude de sermos um periódico de acesso aberto, permite-se o uso gratuito dos artigos em aplicações educacionais e científicas desde que citada a fonte conforme a licença CC-BY da Creative Commons.

Creative Commons Atribuição 4.0 Internacional. 